myoelectric slow waves and contractions recorded from the distal colon. Psychophysiology $1989 ; 26: 26-9$.

2 Kumar D, Williams NS, Waldron D, Wingate DL. Prolonged manometric recording of DL. Prolonged mactity in ambulant human subjects: evidence of periodic activity. Gut subjects: evidence

3 Orkin BA, Hanson RB, Kelly KA. The rectal motor complex. $\mathcal{F}$ Gastrointest Motil 1989; 1 : moto.

4 Kumar D, Thompson PD, Wingate DL. Absence of synchrony between human small intestinal migrating motor complex and rectal motor complex. Am $\mathcal{F}$ Physiol 1990; 258: G171-2.

5 Narducci F, Bassotti G, Gaburri M, Morelli A. Twenty four hour manometric recording of colonic motor activity in healthy man. Gut 1987; 28: 17-25.

6 Bassotti G, Bucaneve G, Pelli MA, Morelli A. Regular contractile patterns of the human colon. $\mathcal{F}$ Gastrointest Motil 1990; 2: 73-8.

7 Bassotti G, Betti G, Pelli MA, Morelli A. Prolonged (24-hour) manometric recording of rectal contractile activity in patients with slow rectal contractile activity in patients with slow
transit constipation. Digestion 1991; 49: 72-7.

8 Waldron DJ, Kumar D, Hallan RI, Wingate DL, Waldron DJ, Kumar D, Hallan RI, Wingate DL,
Williams NS. Evidence for motor neuropathy and reduced filling of the rectum in chronic intractable constipation. Gut 1990; 31: 1284-8.

9 Bassotti G, Gaburri M. Manometric investigation of high-amplitude propagated contractile activity of the human colon. Am $\mathcal{F}$ Physiol 1988; 266: G660-4.

10 Bassotti G, Gaburri M, Imbimbo BP, Rossi L, Farroni F, Pelli MA, et al. Colonic mass movements in idiopathic chronic constipation. Gut 1988; 29: 1173-9.

\section{Increased intestinal permeability in ankylosing spondylitis}

SIR, - We read with great interest the excellent paper by Morris et al (Gut 1991; 32: 1470-2) on intestinal permeability in ankylosing spondylitis but we do not agree, however, with their conclusions.

Using the ${ }^{51} \mathrm{Cr}$-EDTA resorption test ${ }^{12}$ we recently studied gut permeability in inflammatory rheumatic disorders. Intake of nonsteroidal anti-inflammatory drugs (NSAIDs) significantly increases gut permeability irrespective of the underlying disease. Patients with ankylosing spondylitis and with other spondylarthropathies not taking NSAIDs also presented a significant increase of gut permeability compared with controls. This indicates that the disturbance is disease related. Gut permeability was not significantly increased in patients with histological gut lesions on ileocolonoscopy, or in patients with a normal ileum, although patients with ankylosing spondylitis and chronic gut lesions (resembling Crohn's disease) showed a significant increase in gut permeability compared with patients with ankylosing spondylitis and acute gut lesions.

There are several explanations for the absence of a relationship between increased gut permeability and ileocolonoscopic evidence of gut inflammation. On ileocolonoscopy only the terminal aspect of the ileum, which is only a very small part of the small bowel, can be examined. Moreover, the distribution of the observed lesions was patchy. Intake of NSAIDs causes such major disturbances in gut permeability that minor and local inflammation of the ileum would not influence the results of the ${ }^{\text {sI }} \mathrm{Cr}$-EDTA resorption test.

Inflammatory gut lesions were not found in patients with rheumatoid arthritis ${ }^{3}$ taking high doses of NSAIDs for prolonged periods, while such lesions were present in more than 50 patients with spondyloarthropathies ${ }^{+}$who had not taken antiinflammatory drugs. This suggests that primary lesion in the ileocaecal region is associated with the spondyloarthropathies, while intake of NSAIDs probably induces more extensive and diffuse functional disturbances of the entire small bowel.

H MIELANTS E M VEYS M DE VOS C CUVELIER Departments of Rheumatology, Gastroenterology, and Pathology,
Ghent University Hospital, Belgium

1 Mielants H, Goemaere S, De Vos M, Schelstraet $\mathrm{K}$, Goethals $\mathrm{K}$, Maertens $\mathrm{M}$, et al. Intestinal mucosal permeability in inflammatory rheumatic diseases. I. Role of antiinflammatory drugs. $\mathcal{J}$ Rheumatol 1991; 18: 389-93.

2 Mielants H, De Vos M, Goemaere S, Schelstraete $\mathrm{K}$, Cuvelier C, Goethals $\mathrm{K}$, et al. Intestinal mucosal permeability in inflammatory rheumatic mucosal permeability in inflammatory rheumatic 18: $394-400$.

3 Mielants H, Veys EM, Cuvelier C, De Vos M Ileocolonoscopic findings in seronegative spondylarthropathies. $B r \mathcal{J}$ Rheumatol 1988; 27: 95-105.

4 Mielants H, Veys EM, Goemaere S, Goethals K, Cuvelier C, De Vos M. Gut inflammation in the spondyloarthropathies: clinical, radiologic, biologic and genetic features in relation to the type of histology. A prospective study. I Rheumatol 1991; 18: 1542-51.

\section{Reply}

SIR, - We do not feel that the evidence presented by Mielants et al in this letter convincingly shows that there is a primary pathology of the terminal ileum in patients with spondylarthropathies. Although patients with spondylarthropathies not taking non-steroida antiinflammatory drugs (NSAIDs) did have significantly increased permeability compared with the controls, this was, by the authors' own admission, a very small group in whom no details of gut histology are given. Chronic lesions, resembling subclinical Crohns disease, as described by the authors, may have been present and thus affected the results by increasing permeability in some of those patients. $^{12}$

The argument that local or patchy inflammation of the ileum may not affect results of ${ }^{51} \mathrm{Cr}$-EDTA absorption does not seem valid when previous studies have shown that ${ }^{51} \mathrm{Cr}$-EDTA excretion increases towards the end of a nought to six hours collection consistent with increased absorption more distally in the small bowel. ${ }^{3}$ Local inflammation in the ileum would be expected to have a relatively greater effect on ${ }^{51} \mathrm{Cr}$-EDTA results and the lack of correlation between ileocolonoscopic findings and permeability (by Mielants et al) requires further explanation.

The fact that no inflammation was observed in rheumatoid arthritis patients at ileocolonoscopy should be considered in the context of more proximal inflammation and ulceration observed by our group using small bowel enteroscopy. ${ }^{4}$ It may be that NSAID treatment is affecting different areas of the gut preferentially in ankylosing spondylitis and rheumatoid arthritis, thus explaining the increased permeability in rheumatoid arthritis patients on NSAIDs without ileocolonoscopic evidence of inflammation observed by Mielants and colleagues. Overall we find that the evidence for NSAID small bowel damage is more compelling than for a primary abnormality in spondylarthropathy.

A J MORRIS A DUNCAN R I RUSSELL Gastroenterology Unit, Royal Infirmary,
Glasgow G312ER

1 Mielants H, Goemaere S, De Vos M, Schelstraete $\mathrm{K}$, Goethals K, Maertens M, et al. Intestinal mucosal permeability in inflammatory rheumatic diseases. I. Role of antiinflanımatory drugs. f Rheumatol 1991; 18: 389-93.

2 Mielants H, De Vos M, Geomaere S, Schelstraete $\mathrm{K}$, Cuvelier $\mathrm{C}$, Geothals $\mathrm{K}$, et al. Intestinal $\mathrm{K}$, Cuvelier $\mathrm{C}$, diseases. II. Role of disease. $\mathcal{F}$ R heumatol 1991; 18: $394-400$.

3 Elia M, Behrens R, Northrop C, Wraight $P$, Neale G. Evaluation of mannitol, lactolose and " $\mathrm{Cr}-$ labelled ethylenediaminetetra - acetate as labelled ethylenediaminetetra - acetate as markers of intestinal

4 Morris AJ, Madhok R, Sturrock RD, Capell HA, MacKenzie JF. Enteroscopic diagnosis of small bowel ulceration in patients receiving non steroidal antiinflammatory drugs. Lancet 1991; 337: 520 .

\section{Crohn's disease after ileocolic resection}

SIR,-Olaison, Smedh and Sjödahl (Gut 1992; 33: 331-5) have provided endoscopic evidence that in many cases of Crohn's disease renewed ileal ulceration occurs soon after surgical resection; 22 of 30 examined at three months and proportionately more at 12 months. The authors consider that their data support views held by many that the bowel is permanently affected in Crohn's disease and is therefore liable to frequent clinical relapse even after apparent radical resection. Yet some follow up studies have also shown that as many as $25 \%$ of patients remain free of clinical symptoms fo many years or even indefinitely. Nevertheless, with a relapse or recurrence rate as high as it is, it is clearly the responsibility of every physician and surgeon to do all that is possible to stave of renewed activity of the disease. Olaison et al's report suggests that this needs to be done if possible before the onset of clinical symptoms when the disease process will have progressed to extensive ulceration and/or strictures.

Most clinicians at present monitor progress of these patients by regular checks for symptoms and signs of recurrence and test for anaemia, a rise in sedimentation rate and muramidases. Others, influenced by reports such as this one, may be inclined to prescribe maintenance doses of drugs such as aminosalicylates, immunosuppressives or corticosteroids. There is, however, evidence that such measures alone are not always enough That evidence concerns the adverse affect of definitive emotional stress in this disorde which has either been forgotten or overlooked or disbelieved and therefore ignored. The case both for and against it has been reviewed in the section on Crohn's disease in a recent book. Appropriate psychological management of such cases is well within the competence of a non-psychiatrically trained physician once he or she has become aware of what is needed to help these sensitive and vulnerable people to change their previously damaging coping mechanisms in dealing with abrasive interpersonal strife in their immediate environment. How to do this is described with case historie and transcripts. ${ }^{1}$ What so often happens now, however, is that patients, many of them very young, are returned without psychological help to the same abrasive domestic or social environment which immediately preceded the onset or relapse of their disease. Case histories and the few outcome studies available illustrate the value of such intervention in cutting shor relapses when domestic strife escalates and patients find themselves caught in the middle. Before treatment they lack the ability to cope or escape. Many such patients managed in this way remain free of disease for many years or suffer only minor relapses. The authors of the article from a Department of Surgery may be unaware that the first reports on psychosomatic 